\title{
POLÍTICAS EDUCACIONAIS NA AMAZÔNIA: a questão "indígena" no ensino superior
}

\author{
Lucas de Vasconcelos Soares \\ Maria Lília Imbiriba Sousa Colares \\ Maria Antonia Vidal Ferreira
}

Resumo

O artigo visa analisar as políticas de acesso e permanência de estudantes indígenas no Ensino Superior na região amazônica do Brasil, contrapondo tal realidade com os procedimentos históricos adotados pelos órgãos governamentais em torno da efetividade desta premissa na educação. As análises realizadas se constituem de pesquisa bibliográfica e documental, contemplando conquistas para os povos indígenas no Brasil, como a Lei n. 12.711/2012 que incorpora o Sistema de Cotas nas universidades públicas (BRASIL, 2012). Dos resultados obtidos, é possível verificar que houve significativos avanços das políticas educacionais em prol da inserção indígena no ensino superior, bem como estas contribuíram na ampliação do direito à diversidade entre os povos, refletidas em legislações posteriores, como a Lei n. 11.645/2008. Contudo, apesar da recente presença no ensino superior, a questão indígena, atualmente, passa por rupturas, minimizando o caráter compensatório e assumindo um compromisso inclusivo e de responsabilidade social com o desenvolvimento local, consolidando-se como um direito público efetivo. Na Amazônia, as experiências contempladas indicam um sentido positivo, porém, necessário de atenção com financiamento, mediante um cenário de crise educacional no país.

Palavras-chave: educação superior indígena; educação na Amazônia; políticas públicas na Amazônia.

EDUCATIONAL POLICIES IN THE AMAZON: the "indigenous" issue in higher education

Abstract

The article aims to analyze the policies of access and permanence of indigenous students in Higher Education in the Amazon region of Brazil, contrasting this reality with the historical procedures adopted by government agencies around the effectiveness of this premise in education. The analyzes performed consist of bibliographic and documentary research, contemplating achievements for indigenous peoples in Brazil, such as Law n. 12,711/2012 that incorporates the Quota System in public universities (BRASIL, 2012). From the results obtained, it is possible to verify that there were significant advances in educational policies in favor of indigenous insertion in higher education, as well as these contributed to the expansion of the right to diversity among peoples, reflected in subsequent legislation, such as Law n. 11,645/2008. However, despite the recent presence in higher education, the indigenous issue currently undergoes ruptures, minimizing the compensatory character and assuming an inclusive and socially responsible commitment to local development, consolidating itself as an effective public right. In the Amazon, the experiences contemplated indicate a positive sense, however, necessary for attention with financing, in the context of an educational crisis in the country.

Keywords: indigenous higher education; education in the Amazon; public policies in the Amazon.

POLÍTICAS EDUCATIVAS EN LA AMAZONÍA: la cuestión "indígena" en la educación superior

Resumen

El artículo tiene como objetivo analizar las políticas de acceso y permanencia de los estudiantes indígenas en Educación Superior en la región amazónica de Brasil, contrastando esta realidad con los procedimientos 
históricos adoptados por las agencias gubernamentales en torno a la efectividad de esta premisa en la educación. Los análisis realizados consisten en investigación bibliográfica y documental, contemplando logros para los pueblos indígenas en Brasil, como la Ley n. 12.711/2012 que incorpora el Sistema de Cuotas en las universidades públicas (BRASIL, 2012). A partir de los resultados obtenidos, es posible verificar que hubo avances significativos en las políticas educativas a favor de la inserción indígena en la educación superior, y que estos contribuyeron a la expansión del derecho a la diversidad entre los pueblos, reflejado en la legislación posterior, como la Ley n. 11.645/2008. Sin embargo, a pesar de la presencia reciente en la educación superior, el tema indígena actualmente sufre rupturas, minimizando el carácter compensatorio y asumiendo un compromiso inclusivo y socialmente responsable con el desarrollo local, consolidándose como un derecho público efectivo. En la Amazonía, las experiencias contempladas indican un sentido positivo, sin embargo, necesario para la atención con financiamiento, en el contexto de una crisis educativa en el país.

Palabras clave: educación superior indígena; educación en la Amazonía; políticas públicas en la Amazonía.

\section{INTRODUÇÃO}

O estudo visa analisar as políticas de acesso e permanência de estudantes indígenas no Ensino Superior na região amazônica do Brasil, contrapondo tal realidade com os procedimentos históricos adotados pelos órgãos governamentais em torno da efetividade desta premissa na educação.

Entre os objetivos propostos, buscou-se construir uma linha histórica dos acontecimentos e políticas públicas indutoras da inserção indígena no ensino superior do país, afluindo estas para a Amazônia, verificando o acesso, a permanência e demais percursos relacionados à inserção de estudantes indígenas no ensino superior, propiciando reflexões sobre a questão no nível local. As análises realizadas se constituem de pesquisa bibliográfica e documental, utilizando como técnicas de coleta de dados o levantamento teórico sobre o tema; e sistematização de legislações, políticas e programas educacionais contemplados no estudo.

Do embasamento teórico utilizado, o estudo centra-se, inicialmente, nas discussões de Baniwa (2013), Bonin (2012), Lima (2007), Munduruku (2012) e Pereira (2017), seguido pelas contribuições de outros estudiosos do tema. Além destes, ampara-se na análise de documentos legais: a Constituição Federal de 1988, o Estatuto do Índio, o Plano Nacional de Educação (20142024), a Lei n. 12.711/2012, entre outros indicados ao longo do estudo.

Este artigo está composto em dois blocos de análises: a questão indígena no Brasil: caminhos para o ensino superior, descrevendo a dinâmica da relação entre a sociedade e os povos indígenas e a aproximação destes a um modelo educacional de nível superior; e políticas indutoras da inserção indígena no ensino superior, apresentando um panorama histórico das iniciativas, governamentais e populares, voltadas ao cumprimento deste direito aos povos indígenas brasileiros, propiciando reflexões em torno do acesso e permanência de estudantes indígenas no ensino superior, com vista à ampliação e efetivação do direito à educação no país.

\section{A QUESTÃO INDÍGENA NO BRASIL: CAMINHOS PARA O ENSINO SUPERIOR}

Desde o início do processo de colonização no Brasil a questão indígena encontra-se em evidência, principalmente, nas narrativas que inferiorizam estes no decorrer dos anos, tratando-os, muitas vezes, como "meros objetos" e não como humanos em potencial desenvolvimento. É sobre estes povos que, pela sua condição histórica de subordinação aos interesses dos colonizadores e, recentemente, pela capacidade de organização nos movimentos de lutas e resistências em prol de 
direitos, que precisamos refletir. É importante sair de uma visão eurocêntrica e adentrar na perspectiva contemporânea de inclusão social e coletiva.

Estima-se a existência de uma população de, aproximadamente, 817.963 indígenas, espalhados por todo o território nacional, consolidando um número de 305 povos, correspondendo a $0,47 \%$ do número total de habitantes no país. Entre esses dados totais, 315.180 vivem em cidades e 502.783 na zona rural. Em colaboração com a Fundação Nacional do Índio (FUNAI), órgão indigenista oficial do Estado brasileiro, o último censo demográfico (2010) identificou 505 terras indígenas, representando 12,5\% do território nacional. Entre esses povos, verificou-se que $52,9 \%$ dos indígenas não possuíam nenhum tipo de renda, bem como um processo de escolarização abaixo da média, comparado às demais populações não indígenas no país. $\mathrm{Na}$ região amazônica estão 300.000 indígenas, cuja maior concentração se dá no estado do Amazonas (IBGE, 2012).

Historicamente, autores como Munduruku (2012) e Bonin (2012), em estudos sobre o caráter educativo do movimento indígena, expressam uma linha de pensamento voltada ao processo de inserção destes sujeitos no campo educacional, analisando direitos consolidados ao longo dos anos e a representatividade dessas conquistas na promoção da cidadania, inclusão e da educação como bem humano e social. Em um primeiro momento, ressaltam-se dois paradigmas relacionados à figura indígena no Brasil, sendo um deles o exterminacionista, cujo objetivo era a destruição dos povos; e o outro o integracionista, com o entendimento de que estes indivíduos e seus modos de vida eram inferiores aos dos colonizadores e, por conseguinte, estavam fadados ao desaparecimento (MUNDURUKU, 2012, p. 27-30). No campo educacional, desde o século XVI, a oferta de educação escolar aos indígenas esteve interligada a uma perspectiva também integracionista, dando ênfase à recusa da diferença, na tentativa de integração dessas comunidades ao contexto nacional (BONIN, 2012, p. 34). Os autores conversam no sentido de explicitar a existência de tentativas de desapropriação dos indígenas de nossa sociedade, desde articulações de extermínio até as próprias práticas discriminatórias instauradas a fim de enfraquecer as populações, quanto ao reconhecimento social.

Até meados de 1916, os povos indígenas no Brasil, de acordo com o código civil da época, estavam classificados como silvícolas, cuja capacidade era considerada relativa (MUNDURUKU, 2012, p. 35). Em definições legais, entendia-se que índio ou silvícola era “[...] todo indivíduo de origem e ascendência pré-colombiana que se identifica e é identificado como pertencente a um grupo étnico cujas características culturais o distinguem da sociedade nacional" (BRASIL, 1973). De igual modo, entendia-se por comunidade indígena ou grupo tribal um “[...] conjunto de famílias ou comunidades índias, quer vivendo em estado de completo isolamento em relação aos outros setores da comunhão nacional, quer em contatos intermitentes ou permanentes sem, contudo, estarem neles integrados" (BRASIL, 1973). Tais definições explicitam uma visão separatista entre indígenas e sociedade, como se estes vivessem isolados ou distantes dela:

[...] os povos indígenas sempre conviveram numa relação de conflito com a sociedade nacional, por isso a relação existente era a de dois mundos antagônicos, separados por duas sociedades diferentes. De um lado, um povo considerado agente colonizador; de outro lado, os índios. A tentativa de inclusão e inserção dos índios na sociedade dos não índios foi marcada por dificuldades desses povos ao serem inseridos em uma sociedade da qual não faziam parte e com extremas desigualdades (PEREIRA, 2017, p. 39).

Com o passar dos anos, na medida em que o processo de colonização se concretiza na sociedade brasileira acoplado a mudanças na estrutura governamental em nível mundial, somado a movimentos de luta e resistência de populações e grupos locais, inúmeros direitos são 
contemplados na realidade do país, expandindo-se na possibilidade de acesso de camadas menos favorecidas à usuabilidade dessas conquistas. Nesse contexto, encontra-se a educação escolar pública, entendida agora como um direito de todos, por ser um bem indissociável da vida humana, instrumento de preparação para as relações sociais e acesso aos conhecimentos produzidos e sistematizados historicamente, além de constituir um meio de ingresso ao competitivo, exigente e ideológico mercado de trabalho que, entre seus critérios, inclui a seletividade e a definição de competências e habilidades cobradas aos sujeitos sociais. A instituição escolar, enquanto parte da sociedade, constitui um meio de preparação e apropriação dos conhecimentos para atendimento às condições sociais sobrepostas à existência humana.

No entanto, mesmo com o caráter público incorporado aos discursos da nova escola brasileira e de suas condecoráveis legislações educacionais, consolidando a premissa do direito de acesso a todos os cidadãos, ainda assim um modelo europeizado permanece nas bases formativas curriculares e metodológicas do ensino e da estrutura organizacional das instituições no país, com experiências incorporadas de outras realidades, dificilmente, brasileiras — geralmente, práticas “[...] fragmentadas e descontínuas [...]" (BONIN, 2012, p. 35). É nesse cenário de transformações arbitrárias que se mantém, mais uma vez, um modelo educacional proporcional às elites (classes dominantes), distante das particularidades e anseios das massas (classes dominadas). É perceptível que o modelo educacional implantado tende a hegemonizar o ensino, especialmente, público. Esse modelo coloca outros grupos étnico-raciais-culturais em situação de desigualdade, no que tange ao acesso e garantia de direitos e bens sociais, pois, conforme descreve Rodrigues (2018, p. 398), “[...] a experiência mostra que há uma grande distância entre o plano teórico das garantias legais e o da sua implementação. Dificuldades cuja superação de certa forma impelem indígenas a se organizarem para conquistar a efetivação de seus direitos".

É nesse mesmo cenário, e sob moldes ideológicos e excludentes, que ganha espaço no âmbito educacional brasileiro a criação, oferta e implementação do ensino superior, regulamentado pela Lei n. 5.540 de 28 de novembro de 1968, com base em modelo elitista organizacional. Tal modalidade preceitua, entre outras finalidades, o aprimoramento das relações sociais, a apropriação de conhecimentos mais elevados, a formação profissional e intelectual de uma sociedade em desenvolvimento. Com o passar dos anos, este ensino passou por mudanças, dando abertura à inserção de outros sujeitos, incluindo camadas marginalizadas da sociedade. Contudo, é necessário enfatizar que a ampliação do ensino superior no Brasil resulta de intensos debates e esforços coletivos em prol da extensão de um direito que, legalmente, é de todos.

No contexto dos povos indígenas, objeto central do estudo, as influências da Convenção n. 169 da Organização Internacional do Trabalho (OIT) sobre "Povos Indígenas e Tribais", realizada em Genebra (Suíça) em 27 de junho de 1989 e promulgada no Brasil pelo Decreto n. 5.051 de 19 de abril de 2004, aliada à Lei n. 12.711 de 29 de agosto de 2012, também conhecida como Lei de Cotas, constituem importantes marcos para a expansão do ensino superior público a este grupo social, permitindo o ingresso de indígenas e, a partir desta política, a criação de outras políticas, programas e ações que garantem sua permanência nas universidades. A inserção indígena nesse nível de ensino possibilita a elevação cultural, moral e social das massas e uma formação alinhada à responsabilidade e compromisso social. Para Lima (2007, p. 9), a procura do indígena por formação superior pressupõe uma compreensão de que "[...] há dois vieses diferentes, [...] $O$ primeiro deles tem a ver com a educação escolar que foi imposta aos indígenas [...]. O segundo viés passa pela necessidade de se ter profissionais indígenas graduados [...], capazes de articular esses saberes e os conhecimentos tradicionais de seus povos [...]".

Nesse processo de transformação de uma universidade tradicional elitista para uma universidade das massas, encontram-se algumas correntes de pensamento que evocam a democratização, a autonomia e a qualidade, constituindo movimentos em prol da universidade 
popular. Entretanto, ao mesmo tempo em que se defende a democratização do ensino superior, reivindicando autonomia universitária, um grave obstáculo emerge - a conciliação da universidade das massas com a necessária qualidade. É inegável que a universidade e sua abertura às classes menos favorecidas constituem um enorme passo na defesa da democracia na educação, porém, é também visível a condição de que esta não está pronta, ainda, para receber essa população, tornando-se um desafio articular-se com esses contextos socioculturais. Sob essa perspectiva, incluem-se os indígenas enquanto povos que possuem enormes especificidades, comparados aos demais na sociedade, visíveis nos modos de pensar, falar e agir. Tal problemática tende a agravarse na Amazônia, enquanto espaço de singularidades e desafios constantes.

Afinal, os alunos indígenas devem alcançar a universidade ou a universidade precisa alcançá-los? Em que modelo de universidade deve-se ajustar o estudante indígena? Tais questionamentos são relevantes mediante um cenário de crise na educação brasileira, com a desarticulação de direitos e políticas públicas educacionais, no sentido de reforçar sobre qual têm sido os modelos e critérios adotados para a inserção desse público no ensino superior. A seguir, analisaremos o percurso assumido pelas políticas educacionais no país e na Amazônia.

\section{POLÍTICAS INDUTORAS DA INSERÇÃO INDÍGENA NO ENSINO SUPERIOR}

No ano de 1910, no cenário brasileiro, foi criado o Serviço de Proteção aos Índios e Localização de Trabalhadores Nacionais (SPILTN), cujo órgão público, organizado por Marechal Rondon, seu primeiro diretor, era o único responsável por gerir e administrar a política e prestar assistência aos povos indígenas no país. Esta organização foi extinta em 1967, momento de criação da Fundação Nacional do Índio (FUNAI), tornando-a substituta e órgão indigenista oficial do Brasil. Inicialmente, a atuação da FUNAI se consolidava em ações de delimitação, demarcação, regularização e registro de terras indígenas, além da coordenação e implementação de políticas de proteção a essas populações (MUNDURUKU, 2012).

Delineada a função assistencialista, a FUNAI atuava na representatividade dos povos indígenas diante da integração à comunhão nacional, garantindo o cumprimento e alcance de direitos e um possível desenvolvimento social desses indivíduos na luta por reconhecimento, inclusão, respeito e ascensão. A partir disso, inúmeras legislações e demais políticas passam a instalar-se no cenário local, resultantes de investidas populares e de órgãos protecionistas em prol de expansão, acesso e permanência a bens e direitos básicos no país.

Fruto dessas intervenções sociais, a criação da Lei n. 6.001 de 19 de dezembro de 1973, que dispõe sobre o Estatuto do Índio no Brasil, constitui-se como uma das primeiras iniciativas constitucionais de garantia de direitos a populações inferiorizadas na história, principalmente, no que tange a premissas de inserção destes no campo educacional. De acordo com o Artigo $1^{\circ}$, o Estatuto visa regular "[...] a situação jurídica dos índios [...] e das comunidades indígenas, com o propósito de preservar a sua cultura e integrá-los, progressiva e harmoniosamente, à comunhão nacional" (BRASIL, 1973). Do mesmo modo, em parceria com a União, estados, municípios e demais órgãos das administrações indiretas, previa garantir a proteção desses povos e a preservação de seus direitos, visando "[...] I - estender aos índios os benefícios da legislação comum [...]; III respeitar [....] as peculiaridades inerentes à sua condição [...]; VIII - utilizar a cooperação, o espírito de inciativa e as qualidades pessoais do índio, tendo em vista [...] sua integração no processo de desenvolvimento" (BRASIL, 1973).

Referente ao campo da educação, o Artigo 48 da mesma Lei determina a extensão à população indígena brasileira, mediante procedimentos de adaptações necessárias, do "[...] sistema de ensino em vigor no País” (BRASIL, 1973). Recomenda, ainda, de acordo com o Artigo 49, que 
"A alfabetização dos índios far-se-á na língua do grupo a que pertençam, e em português [...]" (BRASIL, 1973), um meio encontrado de possibilitar a inserção desses indivíduos nas relações sociais atuais, contemplando-os com o aprendizado da língua oficial falada no país, garantindo a comunicação real e efetiva entre os povos. Fica garantido, também, pelo Artigo 52 da Lei, “[...] formação profissional adequada, de acordo com o seu grau de aculturação" (BRASIL, 1973). Sobre esse processo de modelamento do índio com vista à sua inserção social, presta-se a afirmativa de Silva, Portela e Matos (2019, p. 292):

Há uma concepção de que a diferença étnica ou cultural poderia fortalecer a desigualdade, tal pensamento caracteriza a insensibilidade às diversidades e promove a perda de características específicas de determinados grupos étnicos, como ocorre com a língua materna de nossos alunos indígenas que são inseridos em outro contexto de interação social onde a língua portuguesa é imposta, seja no processo de aquisição da escrita ou da linguagem oral, desconstruindo a identidade e descaracterizando a ideia de escola bilíngue, numa tentativa discriminada de homogeneização das culturas.

Passados 15 anos da criação do Estatuto do Índio no Brasil, as propostas e finalidades expressas em tal legislação começam a subsidiar outras discussões em prol da garantia dos direitos a esses povos, especialmente, no cenário de elaboração da nova Constituição Federativa da República promulgada em 1988, espaço em que as populações indígenas estiveram presentes na busca pela efetividade de reconhecimento social. Ganhou ênfase o movimento indígena brasileiro, marcado por reivindicações, protestos e ascensão desses, enquanto camadas até então ocultas no campo político da sociedade. "As mudanças [...] foram pautadas pelo movimento indígena brasileiro, que se fez conhecido e respeitado por sua participação decisiva na elaboração da nova Carta Magna [...]” (MUNDURUKU, 2012, p. 36).

Os efeitos desse movimento resultaram em representação e inserção dos povos indígenas na Constituição Cidadã e em legislações e políticas posteriores no país, definindo a premissa legal de que, segundo o Artigo 232, "Os índios, suas comunidades e organizações são partes legítimas para ingressar em juízo em defesa de seus direitos e interesses, intervindo o Ministério Público em todos os atos do processo" (BRASIL, 1988). Finalmente, a nomenclatura silvícola é abolida de documentos oficiais, delegando a esses povos a proteção, o respeito, a inserção social e a garantia de seus direitos. Assim, os indígenas tornam-se, constitucionalmente, legítimos cidadãos brasileiros.

O princípio constitucional de que a educação é um direito de todos, sendo, portanto, um bem público, expresso no Artigo 205 da Constituição de 1988, permite a abertura de outras propostas educacionais que visem contemplar as diversidades, agora reconhecidas oficialmente no país. Seja pela criação de escolas em espaços não alcançados pelo sistema de ensino; na inserção desses povos no ensino oficial; e na implementação de outras modalidades educacionais, entre elas, a educação escolar indígena, por meio da qual os indígenas passam a receber maior atenção no tocante a propostas pedagógicas próprias. $\mathrm{Na}$ rede oficial de ensino, fica instituído, pelo Artigo 210, a fixação de conteúdos mínimos "[...] de maneira a assegurar formação básica comum e respeito aos valores culturais e artísticos, nacionais e regionais" (BRASIL, 1988), possibilitando aos indígenas inseridos nessas redes "[...] a utilização de suas línguas maternas e processos próprios de aprendizagem” (BRASIL, 1988). "[...] Oficializou-se a criação da modalidade/categoria Educação Indígena no sistema nacional de educação fundamentada no fortalecimento da autonomia dos grupos étnicos permitindo à escola ser um agente dos interesses indígenas [...]" (RODRIGUES, 2018, p. 398).

Nesse espaço de transformações educacionais, somam-se aos esforços coletivos as discussões resultantes da Convenção n. 169 (promulgada no Brasil pelo Decreto n. 5.051/2004), 
que passa a ser executada inteiramente como medida legal para fortificar a luta por direitos indígenas no país. Uma das principais contribuições apresentadas se justifica, no Artigo 26, na exigência de que "[...] deverão ser adotadas medidas para garantir aos membros dos povos interessados a possibilidade de adquirirem educação em todos os níveis, pelo menos em condições de igualdade com o restante da comunidade nacional" (BRASIL, 2004), projetando-os à situação de equidade social. Ainda no Decreto n. 5.051/2004, o Artigo 27 ressalta que:

Os programas e os serviços de educação destinados aos povos interessados deverão ser desenvolvidos e aplicados em cooperação com eles a fim de responder às suas necessidades particulares, e deverão abranger a sua história, seus conhecimentos e técnicas, seus sistemas de valores e todas suas demais aspirações sociais, econômicas e culturais (BRASIL, 2004).

Outro acontecimento positivo se dá na criação e promulgação do Decreto n. 26 de 4 de fevereiro de 1991, cuja matéria dispõe sobre a Educação Indígena no Brasil, sendo preciso em delegar ao Ministério da Educação (MEC), de acordo com o Artigo 1" , “[...] a competência para coordenar as ações referentes à Educação Indígena, em todos os níveis e modalidades de ensino, ouvida a FUNAI" (BRASIL, 1991).

É nesse contexto legal que a inserção indígena passou a ser concretizada no campo educacional, quer seja na educação básica como no ensino superior, regulamentando essas possibilidades no advento da Lei n. 9.394 de 20 de dezembro de 1996 (Lei de Diretrizes e Bases da Educação Nacional, LDB). Essa Lei, cujas bases definem como princípios do ensino público, de acordo com o Artigo $3^{\circ}$, a igualdade de condições; liberdade de aprender e ensinar valorizando a cultura e o saber; respeito e apreço à tolerância; gratuidade do acesso; garantia de padrões de qualidade; e contemplação e valorização da diversidade étnico-racial (BRASIL, 1996), incluiu os povos indígenas brasileiros respaldando, assim, todos os povos ao direito e ao acesso à educação escolar, desde o nível básico até o superior.

Entendida a educação como um bem público, pressupõe-se que a missão pública da educação superior é formar cidadãos competentes e comprometidos com o projeto social do país, dado que, segundo o Artigo 43 da LDB, tal nível de ensino tem por finalidade:

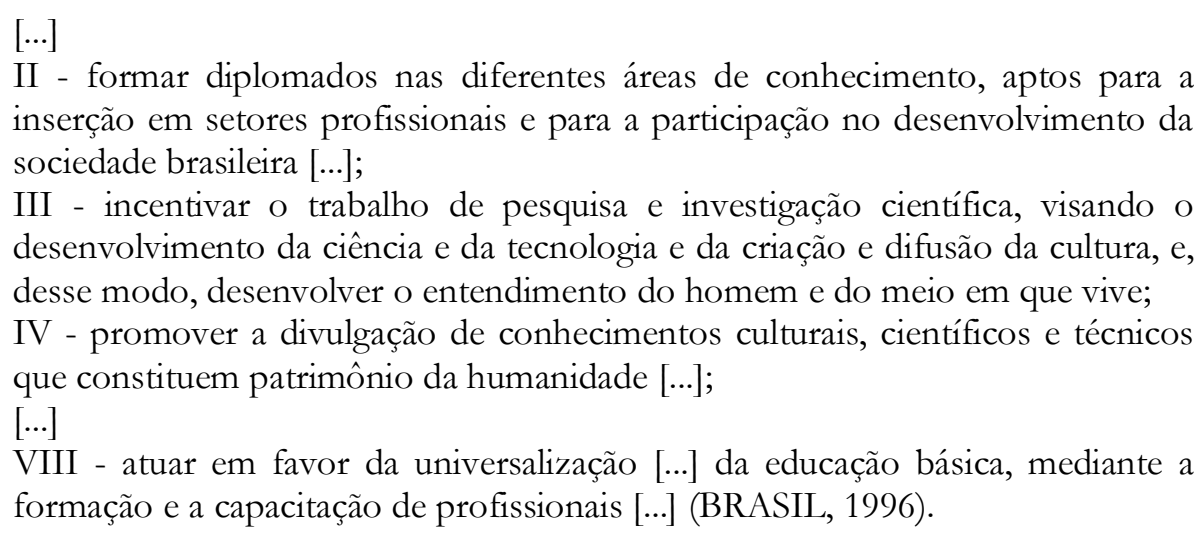

A educação superior possibilita a ampliação de conhecimentos produzidos, a elevação social, histórica e moral dos indivíduos, a intervenção em problemáticas na sociedade e contribui para o desenvolvimento científico, político, econômico e social do país. "[...] A formação precisa ser continuada, coletiva e abrangente" [...]. (COLARES, 2018, p. 32). Para as populações menos favorecidas, o acesso ao ensino superior constitui um passo na efetividade do direito à educação, pois, considerando todas as finalidades expressas sobre tal nível de ensino, a inserção dessas 
populações tende a propiciar o acesso a conhecimentos que podem servir de base para lutas em prol da transformação social.

Entretanto, assegurar a educação como direito de todos, a ser garantido pelo Estado, não é suficiente para que a educação superior possa cumprir seu papel estratégico. É preciso garantir a qualidade acadêmica. Essa condição se justifica no decorrer dos anos, mediante condições sobrepostas de acesso dos estudantes a esse nível de ensino, caracterizado pela aplicação de extensas provas conteudistas e pela classificação dos melhores candidatos ao final, o conhecido vestibular. Com a LDB n. 9394/96, Artigo 44, inciso II, tal condição é substituída pela expressão "Processo Seletivo" para ingresso no ensino superior. Essa mudança possibilita às universidades a autonomia para organizar e pensar outros formatos de ingresso ${ }^{1}$ dos estudantes, considerando a articulação desse nível com o ensino médio e demais órgãos normativos dos sistemas de ensino, conforme definido no Artigo 51, que ressalta:

As instituições de educação superior credenciadas como universidades, ao deliberar sobre critérios e normas de seleção e admissão de estudantes, levarão em conta os efeitos desses critérios sobre a orientação do ensino médio, articulando-se com os órgãos normativos dos sistemas de ensino (BRASIL, 1996).

A Lei n. 12.711/2012, também conhecida como Lei de Cotas, tem como finalidade destinar, em cada processo seletivo realizado nas instituições de educação superior, um percentual mínimo, segundo o Artigo $1^{\circ}$, de "[...] 50\% (cinquenta por cento) de suas vagas para estudantes que tenham cursado integralmente o ensino médio em escolas públicas", sendo metade dessas vagas $(50 \%)$ reservadas aos "[...] estudantes oriundos de famílias com renda igual ou inferior a 1,5 saláriomínimo (um salário-mínimo e meio) per capita" (BRASIL, 2012). Nessa divisão, de acordo com o Artigo $3^{\circ}$, em cada instituição federal de ensino superior, as vagas serão preenchidas "[...] por autodeclarados pretos, pardos e indígenas [...] em proporção ao total de vagas no mínimo igual à proporção respectiva de pretos, pardos e indígenas [...] na população da Unidade da Federação onde está instalada a instituição [...]" (BRASIL, 2012), de acordo com o último Censo do IBGE.

Ainda no curso da lei, esta seria implementada e avaliada no país sob o acompanhamento do MEC e da Secretaria Especial de Políticas de Promoção da Igualdade Racial (extinta em 2015), sempre ouvindo o órgão indigenista oficial, nesse caso, a FUNAI, conforme Artigo $6^{\circ}$. No prazo de 10 anos, conforme Artigo $7^{\circ}$, deverá ser feita a avaliação da legislação no país (BRASIL, 2012).

A Lei de Cotas tem como finalidade, entre outras, corrigir uma histórica exclusão social e educacional desses segmentos, compondo o rol de políticas afirmativas da sociedade brasileira. Esta obrigação da reserva de vagas a estudantes negros, pardos e indígenas se justifica pela distorção histórica para com este contingente populacional formado, que contribuiu com a economia e o desenvolvimento do país, porém, não usufruiu dessa realidade.

$\mathrm{Na}$ defesa de uma "universidade para todos", a Lei de Cotas integra um conjunto de ações do Governo Federal que visa ampliar e democratizar o acesso ao ensino superior no Brasil, possibilitando, a partir desta, um fluxo ingressante cada vez mais diverso, proveniente de escolas públicas do campo e da cidade. Porém, outra questão se impõe: poucas vagas ofertadas para uma expressiva demanda. Diante do problema, destaca-se a preocupação apresentada por Lima (2007, p. 20):

\footnotetext{
$1 \mathrm{O}$ ingresso de estudantes indígenas nas universidades ocorre em variados processos, sendo que grande parte das instituições implementou metodologias específicas, como a indicação de candidatos feita por líderes comunitários e/ou por organizações e órgãos indígenas, acompanhada de provas específicas e entrevistas, entre outros meios.
} 
Ao incluir os indígenas nas universidades há que se repensar as carreiras universitárias, as disciplinas, abrir novas (e inovadoras) áreas de pesquisa, selecionar e repensar os conteúdos curriculares que têm sido ministrados, e testar o quanto estruturas, que acabaram se tornando tão burocratizadas e centralizadoras, podem suportar se colocar ao serviço de coletividades vivas, histórica e culturalmente diferenciadas.

$\mathrm{Na}$ região amazônica, entre as instituições de ensino superior existentes, a Universidade Federal do Oeste do Pará (UFOPA) ofertou, no processo seletivo de 2019, 1.413 vagas aos cursos de graduação, sendo 711 reservadas ao sistema de ingresso por cotas. Este procedimento foi adotado em 2011, criando-se o Processo Seletivo para Indígenas (PSEI) que, neste ano, recebeu mais de 600 indígenas inscritos para 81 vagas disponibilizadas. Atualmente, a instituição dispõe de 507 indígenas matriculados no ensino superior (UFOPA, 2019). Em 2020, objetiva-se ampliar o sistema de cotas para o ingresso de estudantes indígenas em todos os programas de pós-graduação da UFOPA, conforme a aprovação da Resolução n. 314 (UFOPA, 2020). Corroborando esta realidade, é notório saber que a Universidade Federal do Amazonas (UFAM) formou, entre 2013 e 2018, “[...] 263 alunos indígenas nas modalidades Licenciatura Indígena Políticas Educacionais e Desenvolvimento Sustentável e Formação de Professores Indígenas” (Site Amazônia Real, 2019).

Nesse processo de consolidação da inserção indígena no ensino superior, destacam-se políticas e legislações educacionais que corroboraram a efetivação desse direito público no país, entre elas o Parecer n. 14/99 que dispõe sobre as Diretrizes Curriculares Nacionais da Educação Escolar Indígena; a Lei n. 11.645/2008 que inclui no currículo oficial a obrigatoriedade da temática História e Cultura Afro-Brasileira e Indígena no país; e o Decreto n. 6.881/2009 que trata da Educação Escolar Indígena quanto à organização em territórios etnoeducacionais - todas importantes para a valorização desses atores no campo educacional.

Dessas ações e legislações específicas resultou uma série de iniciativas que visam a concretizar definições constitucionais, geralmente pensadas a partir de reivindicações para a melhoria do ensino no país. Entre essas medidas de apoio à inserção indígena no ensino superior, destacam-se: o Programa de Bolsa Permanência (PBP) ${ }^{2}$; o Programa de Apoio à Formação Superior e Licenciaturas Interculturais Indígenas (PROLIND) ${ }^{3}$; o Programa de Desenvolvimento Acadêmico Abdias do Nascimento ${ }^{4}$; entre outras, realizadas em nível nacional e local.

No contexto amazônico, hoje são 12.747 indígenas matriculados em universidades da região Norte, sendo 4.383 em instituições públicas e 8.364 na rede privada. No âmbito do Programa de Bolsa Permanência foram inscritos 19.428 estudantes em todo o Brasil, entre os quais 2.400 indígenas (Site Amazônia Real, 2019).

Outro amparo legal pode ser visto na promulgação da Lei n. 13.005 de 25 de junho de 2014, cuja finalidade foi instituir o Plano Nacional de Educação (PNE), decênio 2014-2024 que, por meio da Meta 12, visa "[...] elevar a taxa de matrícula na educação superior [...] assegurada a qualidade da

\footnotetext{
2 Instituído pelo Governo Federal, o Programa visa à concessão de auxílio financeiro a estudantes do ensino superior em situação de vulnerabilidade socioeconômica e para indígenas e quilombolas. O valor pago é, geralmente, de $\mathrm{R} \$ 400,00$, porém, estudantes indígenas e quilombolas recebem um valor diferenciado, por disporem de condições específicas com relação à organização social de suas comunidades e seus modos de viver.

${ }^{3}$ Visa a apoiar projetos de cursos de licenciaturas específicas que proporcionem a formação de professores indígenas para o exercício da docência (nos anos finais do ensino fundamental e no ensino médio) nas escolas indígenas, por meio da integração de ensino, pesquisa e extensão nas universidades públicas brasileiras.

${ }_{4}$ Visa a propiciar a formação e capacitação de estudantes indígenas com elevada qualificação em universidades, instituições de educação profissional e tecnológica e centros de pesquisa no Brasil e no exterior, possibilitando a estes em formação, a experiência da mobilidade.
} 
oferta e expansão [...] no segmento público" (BRASIL, 2014). É deste mesmo Plano que resulta o compromisso firmado na estratégia 12.5 , visando a:

Ampliar as políticas de inclusão e de assistência estudantil dirigidas aos(às) estudantes de instituições públicas [...] na educação superior, de modo a reduzir as desigualdades étnico-raciais e ampliar as taxas de acesso e permanência [...] de estudantes egressos da escola pública, afrodescendentes e indígenas [...] de forma a apoiar seu sucesso acadêmico (BRASIL, 2014).

O referido documento soma-se às diretrizes, políticas e ações de incentivo à consolidação do direito à educação no país, principalmente, voltadas às camadas inferiorizadas da sociedade. Sob essa expansão do ensino superior, o Plano apresenta duas estratégias fundamentais na concretude do processo educacional: a 12.9, que visa a "[...] ampliar a participação proporcional de grupos historicamente desfavorecidos na educação superior, inclusive mediante a adoção de políticas afirmativas, na forma da lei" (BRASIL, 2014); e 12.13, cuja proposta prevê a expansão de “[...] atendimento específico a populações do campo e comunidades indígenas e quilombolas, em relação a acesso, permanência, conclusão e formação de profissionais para atuação nessas populações" (BRASIL, 2014). Assim, a proposta consolida-se como um amparo na garantia da diversidade, na implementação de ações afirmativas e na promoção do desenvolvimento social de povos, ainda distantes, do acesso ao bem público que é a educação.

Ao se analisar o conjunto e percurso das políticas públicas selecionadas no estudo, é visível o crescente reconhecimento da importância da educação básica e superior, não apenas por ser determinante para a formação social e acadêmico-profissional e para atividades de pesquisa em nível científico e tecnológico, mas igualmente em função da posição estratégica que o Brasil ocupa nas políticas públicas voltadas à cidadania democrática e à justiça social.

Contudo, apesar dos significativos avanços, precisamos destacar que a implementação de políticas dessa natureza depende de condições concretas e subsídios às universidades, para sua incorporação efetiva ao ensino superior, necessitando de análises em currículos e propostas pedagógicas; realizando exercícios de verificação da prática com a legislação em vigor, tendo em vista o cumprimento do direito constitucional, dado que "[...] não basta disponibilizar sistemas de cotas, mas complementá-las e reforçá-las com projetos e programas que possibilitem o apoio e acompanhamento dos acadêmicos indígenas" (BANIWA, 2013, p. 20). No caso da educação superior indígena, há que se pensar nas finalidades do conhecimento que esse povo precisa para sua emancipação. Os povos indígenas "[...] não gostariam de serem enquadrados pelas lógicas academicistas que alimentam e sustentam os processos de reprodução do capitalismo individualista [...]" (BANIWA, 2013, p. 19).

É nesse contexto que Bonin (2012, p. 33-34) destaca que “[...] os povos indígenas têm afirmado que assumir a educação escolar é um grande desafio, e a razão principal [...] de serem lógicas distintas a organização da escola e a vida em suas comunidades".

Tais reflexões são importantes no sentido de analisar qual tem sido a agenda das políticas públicas, quanto à inserção indígena no ensino superior. Considerem-se aí as particularidades desse grupo social histórico e o contexto atual da sociedade, de forma que possam inseri-los, assim como aos demais povos, no projeto nação que visa ao desenvolvimento econômico, político e social. Apesar da existência de conflitos entre interesses dos grupos indígenas e o modelo de sociedade incorporado, principalmente, de grupos instalados na região amazônica, ainda assim, pela análise realizada, é possível sinalizar um avanço no campo legal na expansão do ensino superior e na inserção de estudantes indígenas nesse nível de ensino. Mesmo sabendo dos desafios relacionados, "[...] o acesso e a permanência dos indígenas no ensino superior revelam a existência de um desafio comum a ser enfrentado por todas as instituições [...]: dedicar atenção às condições materiais e de 
infraestrutura, bem como a preparação didático-pedagógica de docentes [...]” (PEREIRA, 2017, p. 180).

No contexto amazônico, em 2017, uma turma com 41 indígenas de cinco aldeias foi diplomada na Universidade Federal do Amapá, curso de Licenciatura Intercultural Indígena ${ }^{5}$. Em 2020, na Universidade Federal do Oeste do Pará, ocorreu a defesa de Mestrado em Educação de uma estudante indígena ${ }^{6}$ da região do Arapiuns $^{7}$. Ambos os acontecimentos sinalizam avanços, ainda que, mínimos, na incorporação desse público ao ensino superior, especialmente, na Amazônia brasileira. Muito mais do que a concretização de um direito, este fato resulta na apropriação de novos formatos de desenvolvimento social das populações indígenas, quanto à valorização cultural e à preservação de suas memórias e saberes históricos - elementos fundamentais na história da educação do país e do mundo. Em linhas gerais, as políticas estão caminhando alinhadas a suas concepções originárias.

\section{ALGUMAS CONSIDERAÇÕES}

Dos resultados obtidos ao longo do estudo, é possível verificar que houve significativos avanços das políticas educacionais em prol da inserção indígena no ensino superior, assim como contribuíram na ampliação do direito à diversidade entre os povos, refletida em legislações posteriores, como a Lei n. 11.645/2008. Contudo, apesar da recente presença no ensino superior, a questão indígena, atualmente, passa por rupturas, minimizando o caráter compensatório, para assumir um compromisso inclusivo e de responsabilidade social com o desenvolvimento local, consolidando-se como um direito público efetivo. $\mathrm{Na}$ Amazônia, as experiências contempladas indicam um sentido positivo, porém, que necessitam de atenção com financiamento, mediante o cenário de crise educacional no país.

O percurso trilhado, desde a Constituição de 1988 até a Lei de Cotas em 2012 e demais políticas posteriores, sinaliza importantes conquistas de direitos, traduzidas em leis de cunho assistencialista e protecionista, uma vez que no cerne desses acontecimentos estiveram os movimentos organizados na luta em prol do coletivo, como o movimento indígena brasileiro. Esse movimento se destacou por apresentar resistência e garantir sua inserção nos mecanismos legais do país, conquistando lugar no campo educacional, conforme o estudo evidencia. É sob essa lógica que a inserção de povos indígenas no ensino superior pode ser vista como possibilidade de transformação social, pois permite a consciência de classes e o empoderamento popular.

Apesar dos avanços, é visível a necessidade de fortalecimento das políticas de ação afirmativa de inclusão de estudantes indígenas no ensino superior. Ações que ultrapassem o simples acesso e garantam o êxito acadêmico-profissional desses estudantes. Ou seja, políticas pedagógicas e metodológicas institucionalizadas, pautadas nas características desse grupo social. É nesse contexto que vale destacar que às dificuldades dos estudantes se acrescentam as dos professores, nem sempre preparados para receber esse público. Necessitamos, portanto, de análise, avaliação e reformulação no campo teórico-conceitual das políticas e legislações projetadas para a educação superior, incluindo as diversidades. Em se tratando do nível local, necessitamos de uma política pública educacional na e da Amazônia e suas singularidades.

\footnotetext{
${ }^{5}$ Noticiado pelo site G1 Amapá. Ver reportagem em https://g1.globo.com/ap/amapa/noticia/turma-com-indigenasde-cinco-tribos-se-forma-na-universidade-federal-do-amapa.ghtml.

${ }^{6}$ Noticiado no site da instituição. Ver reportagem em http://www.ufopa.edu.br/ufopa/comunica/noticias/ufopa-teraprimeira-dissertacao-de-mestrado-de-estudante-indigena/.

${ }^{7}$ Conjunto de comunidades localizadas na divisa do estado do Pará com o Amazonas.
} 


\section{REFERÊNCIAS}

BANIWA, Gersem. A lei das cotas e os povos indígenas: mais um desafio para a diversidade. In: Cadernos do Pensamento Crítico Latino-Americano. México: Forum, 2013, p. 18-21. Disponível em: http://flacso.redelivre.org.br/files/2014/12/XXXVcadernopensamentocritico.pdf. Acesso em: 22 mar. 2020.

BONIN, Iara Tatiana. Educação escolar indígena e docência: princípios e normas na legislação em vigor. In: BERGAMASCHI, Maria Aparecida; ZEN, Maria Isabel Habckost Dalla; XAVIER, Maria Luisa Merino de Freiras (org.). Povos indígenas e educação. 2. ed. Porto Alegre: Mediação, 2012, p. 3348.

BRASIL. Constituição Federativa da República do Brasil de 1988. Brasília: Senado, 1988. Disponível em: http://www.planalto.gov.br/ccivil 03/constituicao/constituicaocompilado.htm. Acesso em: 24 mar. 2020.

BRASIL. Decreto n. 26 de 4 de fevereiro de 1991. Dispõe sobre a Educação Indígena no Brasil. Brasília: Senado, 1991. Disponível em: http://www.planalto.gov.br/ccivil 03/decreto/19901994/D0026.htm. Acesso em: 20 mar. 2020.

BRASIL. Decreto n. 5.051 de 19 de abril de 2004. Promulga a Convenção n. 169 da Organização Internacional do Trabalho (OIT) sobre Povos Indígenas e Tribais. Brasília: Senado, 2004. Disponível em: http://www.planalto.gov.br/ccivil_03/_ato2004-2006/2004/decreto/d5051.htm. Acesso em: 22 mar. 2020.

BRASIL. Lein. 6.001 de 19 de dezembro de 1973. Estatuto do Índio. Brasília: Senado, 1973. Disponível em: http://www.planalto.gov.br/ccivil 03/Leis/L6001.htm. Acesso em: 23 mar. 2020.

BRASIL. Lei n. 9.394 de 20 de dezembro de 1996. Lei de Diretrizes e Bases da Educação Nacional. Brasília: Senado, 1996. Disponível em: http://www.planalto.gov.br/ccivil_03/leis/19394.htm. Acesso em: 22 mar. 2020.

BRASIL. Lei n. 12.711 de 29 de agosto de 2012. Dispõe sobre o ingresso nas universidades federais e nas instituições federais de ensino técnico de nível médio. Brasília: Senado, 2012. Disponível em: http://www.planalto.gov.br/ccivil 03/ ato2011-2014/2012/lei/112711.htm. Acesso em: 20 mar. 2020.

BRASIL. Lei n. 13.005 de 25 de junho de 2014. Institui o Plano Nacional de Educação (2014-2024). Brasília: Senado, 2014. Disponível em: http://www.planalto.gov.br/ccivil 03/ ato20112014/2014/lei/113005.htm. Acesso em: 22 mar. 2020.

COLARES, Anselmo Alencar. A educação superior e os desafios da prática docente. Revista Exitus, Santarém, Pará, v. 8, n. 1, p. 17-33, jan./abr. 2018. Disponível em: http://www.ufopa.edu.br/portaldeperiodicos/index.php/revistaexitus/article/view/404/315.

Acesso em: 16 abr. 2020.

IBGE. Instituto Brasileiro de Geografia e Estatística. Os indígenas no Censo Demográfico 2010: primeiras considerações com base no quesito cor ou raça. Rio de Janeiro, 2012. Disponível em: https://indigenas.ibge.gov.br/images/indigenas/estudos/indigena censo2010.pdf. Acesso em: 19 mar. 2020.

LIMA, Antonio Carlos de Souza. Educação Superior para indígenas no Brasil: sobre cotas e algo mais. In: Seminário Formação Jurídica e Povos Indigenas. Belém, Pará: LACED, 2017, p. 1-28. Disponível em: http://flacso.redelivre.org.br/files/2013/02/1019.pdf. Acesso em: 24 mar. 2020.

MUNDURUKU, Daniel. O caráter educativo do movimento indígena (1970-1990). São Paulo: Paulinas, 2012. 
PEREIRA, Terezinha do Socorro Lira. Os indígenas e o Ensino Superior na Amazônia: realidade e perspectivas da Política de Ação Afirmativa da Universidade Federal do Oeste do Pará (2010-2015). 249f. Dissertação de Mestrado em Educação. Universidade Federal do Oeste do Pará, Santarém, 2017.

RODRIGUES, Gilberto César Lopes. Quando a escola é uma flecha: educação escolar indígena e territorialização na Amazônia. Revista Exitus. Santarém, Pará, v. 8, n. 3, p. 396-422, set./dez. 2018. Disponível em: http://www.ufopa.edu.br/portaldeperiodicos/index.php/revistaexitus/article/view/651. Acesso em: 21 mar. 2020.

SILVA, Claudina Miranda; PORTELA, Selma Maria Cunha; MATOS, Maristela Bortolon de. Educação escolar e interculturalidade: a inserção do aluno indígena no contexto urbano em Boa Vista - RR. Revista Teias, Rio de Janeiro, v. 20, n. 56, p. 281-295, jan./mar. 2019. Disponível em: https://www.e-publicacoes.uerj.br/index.php/revistateias/article/view/34105. Acesso em: 24 mar. 2020.

Sites consultados:

AMAZÔNIA REAL, 2019. Disponível em: https://amazoniareal.com.br/educacao-indigenainclusao-requer-valorizacao-dos-povos-da-amazonia-nas-universidades/. Acesso em: 23 mar. 2020.

UFOPA, 2019. Disponível em: http://www.ufopa.edu.br/ufopa/comunica/noticias/ufopa-10anos-contribuicoes-para-a-educacao-no-oeste-do-para/. Acesso em: 19 mar. 2020.

UFOPA, 2020. Disponível em: http://www.ufopa.edu.br/ufopa/comunica/noticias/ufopa-teraprimeira-dissertacao-de-mestrado-de-estudante-indigena/. Acesso em: 20 mar. 2020.

Submetido em março 2020.

Aprovado em abril 2020.

\section{Informações do(as) autor(as)}

Lucas de Vasconcelos Soares

Mestrando em Educação pelo Programa de Pós-graduação em Educação (PPGE) da Universidade Federal do Oeste do Pará (UFOPA). Graduado em Licenciatura em Pedagogia pela UFOPA. Bolsista

Coordenação de Aperfeiçoamento de Pessoal de Nível Superior (CAPES)

E-mail: lu.cas.soares@bol.com.br

ORCID: http://orcid.org/0000-0002-5784-8307

Link Lattes: $\underline{\text { http://lattes.cnpq.br/7538516067447773 }}$

Maria Lília Imbiriba Sousa Colares

Doutora e pós-doutora em Educação pela UNICAMP. Docente do curso de Pedagogia, do Programa de

Pós-graduação em Educação da UFOPA e do Programa de Pós-graduação em Educação da Amazônia

E-mail: lilia.colares@hotmail.com

ORCID: http://orcid.org/0000-0002-5915-6742

Link Lattes: http://lattes.cnpq.br/9671465461954562

Maria Antonia Vidal Ferreira

Doutora em Educação pela UNICAMP. Docente do Magistério Superior na UFOPA

E-mail: ferreira-mv@uol.com.br

ORCID: http://orcid.org/0000-0002-9127-8555

Link Lattes: http://lattes.cnpq.br/0002949972952826 